1. BDS, MSc

Assistant Professor Community and Preventive Dentistry

Peshawar Dental College, Peshawar.

2. BDS, MPH

Assistant Professor Community and

Preventive Dentistry

Peshawar dental College, Peshawar.

Associate Professor Prosthodontics, Peshawar Dental College, Peshawar.

Assistant Professor Community and

Preventive Dentistry

Peshawar Dental College, Peshawar.

5. BDS, MSc

Assistant Professor Community and Preventive Dentistry

6. BDS, MSc

Assistant Professor Community and

Preventive Dentistry

Peshawar Dental College, Peshawar.
3. BDS, FCPS

4. BDS, MSc

Peshawar Dental College, Peshawar.

\section{A COMPARATIVE STUDY OF ORAL HEALTH IN PRECLINICAL AND CLINICAL YEARS OF UNDERGRADUATE DENTAL STUDENTS OF PESHAWAR BY USING DECAY-MISSING FILLED TEETH (DMFT) INDEX.}

Zia Ur Rehman Khalil', Aamir Hameed², Muhammad Raza ${ }^{3}$, Aliya Khan ${ }^{4}$, Kanwal Nazir ${ }^{5}$, Amjid Khattak

ABSTRACT... Objectives: The present study aim was to compare oral health status among the undergraduate dental students of the preclinical and clinical years. Study Design: Crosssectional comparative survey. Setting: Preclinical and clinical Dental students of all dental colleges of district Peshawar. Period: 15 December 2016 to 14 May 2017. Material \& Methods: Clinical examination was conducted among the undergraduate students in all the dental colleges of district Peshawar. The sample was drawn from both the preclinical first year and the clinical final years. Examination was done to evaluate decayed tooth component of DMFT. The questionnaire included demographic details and questions on the students' oral health practices. A clinical oral examination was done to evaluate decayed tooth component of DMFT. Results: Chi-square analysis was performed for group comparisons of data. Statistically there is a trend of significance (0.074). In the pre-clinical group almost $66.3 \%$ of students had bad oral health status while in the clinical group comparatively a low percent of students (33.7\%) had poor oral health status. Conclusion: Oral health status and oral hygiene practices of dental students had improved as they advances towards clinical years.

Correspondence Address:

Dr. Muhammad Raza

Department of Prosthodontics

Peshawar Dental College, Peshawar.

hmraza77@yahoo.com

Article received on:

02/03/2019

Accepted for publication:

21/10/2019

Key words: $\quad$ Caries, Education, Oral Health. DMFT

Article Citation: Khalil Zia Ur Rehman, Hameed A, Raza M, Khan A, Nazir K, Khattak A. A comparative study of oral health in preclinical and clinical years of undergraduate dental students of Peshawar by using decayed missing filled teeth (DMFT) index. Professional Med J 2020; 27(7):1340-1345. DOI: 10.29309/TPMJ/2020.27.07.3337

\section{INTRODUCTION}

Oral health is a comfortable and functional dentition, which allows an individual to continue their social role without any complications. Globally oral cavity diseases are considered to be major public health problem as they can affect anyone regardless of gender, age, ethical or social status with bearing most costly treatments. ${ }^{1-5}$ Although there is a marked improvement in dental health in many developed countries but its prevalence has been reported to be on the rise in some developing countries ${ }^{3}$ contributed by many factors either directly or indirectly related to oral hygiene maintenance. .-5 $^{4-2}$ at leads to plaque layer proliferation resulting in acid production which is associated to development of dental caries and periodontal diseases. ${ }^{1}$

Amongst the oral diseases, dental caries is the most prevalent in the industrial and lower income countries owing to its complex etiology. ${ }^{3-4}$ Study done in 2003 by WHO showed that most adults worldwide have experienced caries, with the disease being most prevalent in Asian and Latin American countries and least prevalent in African countries. ${ }^{5}$ According to Global Burden of Disease (GBD) 2010, Oral disorders affected 3.9 billion people while untreated caries in permanent teeth being the most prevailing condition with an overall prevalence of $35 \%$ for all ages combined. ${ }^{6}$ In the past two decades, the overall prevalence and severity of dental caries is reported to be on a decline, still this largely preventable disease is most common, rises significantly with age, and remains a public health problem. ${ }^{7}$

In Pakistan, oral health trends have shown considerably unsatisfactory results. ${ }^{8}$ Dentists in general are more concerned with the treatment of oral diseases as compare to the prevention and promotion of oral health. ${ }^{9}$ The 2003 National oral health pathfinder survey showed that only $3 \%$ of 
the oral preventive services (examination, scaling and prophylaxis) were availed by the patients who were experiencing different dental diseases. ${ }^{10}$

Dental academic institutions are considered the essential keystones that reflects nation's oral health trends. ${ }^{11}$ The emerging dentists and dental students play a major role in health promotion through providing preventive information to the population. It is therefore essential that their own oral health knowledge be up-to-date. In turn their oral health/ oral habits, reflect awareness and understanding of preventive dental procedures conforming to the expectation of the concern community. ${ }^{12}$

The future Dentists are expected to educate and promote public awareness regarding oral health in the most effective way. This in turn reflects their understanding of the importance of disease prevention and their commitment to improving their patient's oral health. ${ }^{13}$ No research or a study is a perfect attempt, it's along the way one understands and appreciates how to improve upon the design and better analyze the problems. Rational of the study, as no such study conducted in our area and no data available regarding oral health status and hygiene practices, so the present study was designed. It will help the future as well as present dentists in education and promotion of public awareness regarding oral health.

\section{MATERIAL \& METHODS}

The present study was undertaken to assess Oral health status of dental students through a crosssectional comparative survey. This survey was conducted in all the dental colleges of Peshawar city. The total population of the present study included all the undergraduate students of district Peshawar. This population was further divided in to two groups, the preclinical and clinical group, for the purpose of comparison. First year and second year were included in the preclinical group. Third and the Final year students were group as the clinical group. For the purpose of this study, consciences of all the students were done, present on the day of data collection that consented to participate in the study. All the students either absent on the day of data collection or missing due to other reasons were excluded from the study. All the examinations were carried out by one examiner following the methodology and criteria set by the WHO under standard dental light source (20 000 lux) on a functional dental chair. The third molars were not included in the study. The purpose of the study was explained to the participants and Informed consent was obtained before commencing with the questionnaire. Participants were informed about the procedure to be followed and the nature of participation expected during the examination session. They were also informed that participation to the study was voluntary and they could withdraw from the study at any time. The DMFT check list was provided with each of the questionnaire, to be filled by the examining dentist.

In order to assess the oral health status of the students by using the likert scale ,the range of the DMFT score was calculated by taking difference of the maximum(16) and minimum(2) score of the data. This difference ${ }^{14}$ was divided by the number of the groups (2) and the cut off point for oral health status was accessed, which was 7. Thus DMFT 2 to 9 was mark as good status while DMFT scores between 10 and 16 were mark as bad oral health status. An arthematic mean of the target variables were compute using SPSS version 22. Chi-Square test was used to evaluate differences in the distribution of all variables, by level of education at $95 \%$ confidence interval (when $\mathrm{p} \leq 0.05$ ).

\section{RESULTS}

The DMFT scores of the dental students during the clinical examination were used to determine their frequency of dental caries.

The average DMFT score of the whole sample was $3.5 \%$ (Table-I). Out of the total sample of students, mean dmft of the preclinical students were $3.7 \%$. Amongst the clinical students mean dmft score were $3.2 \%$.

In preclinical group $44 \%$ of the teeth were decayed, missing teeth were $1.7 \%$, filled teeth were $11.3 \%$ whereas in clinical group $20 \%$ had 
decayed $4.1 \%$ were missing and $19 \%$ were filled. (Table-I).

From the total sample examined, only $64 \%$ students were observed with decayed teeth, $5.7 \%$ with missing teeth and $30.5 \%$ with filled teeth. (Table-I).
In group comparison of oral health status between preclinical and clinical groups $50.5 \%$ of the preclinical students and $49.5 \%$ of the students were having good oral health status (DMFT 2-9). In preclinical group 66\% were having bad oral health status (DMFT 10-16) whereas in clinical group only $33 \%$ of the participants were having bad oral health status (Table-II).

\begin{tabular}{|l|c|c|c|c|c|}
\hline \multirow{2}{*}{ Education Level } & \multicolumn{4}{|c|}{ DMFT Scores } & \multicolumn{2}{c|}{$\begin{array}{c}\text { Mean Group } \\
\text { DMFT }\end{array}$} \\
\cline { 2 - 6 } & Decay Teeth & Missing Teeth & Filled Teeth & $150(11.3 \%)$ & $761(57 \%)$ \\
\hline Pre-clinical group & $589(44 \%)$ & $22(1.7 \%)$ & $252(19 \%)$ & $572(43 \%)$ & $3.7 \%$ \\
\hline Clinical group & $265(20 \%)$ & $55(4.1 \%)$ & $402(30.5 \%)$ & $1333(100 \%)$ & $3.5 \%$ \\
\hline Total & $854(64 \%)$ & $77(5.7 \%)$ & \multicolumn{2}{|c|}{ Table-I. The Total DMFT scores of dental students. } \\
\hline
\end{tabular}

\begin{tabular}{|l|c|c|c|}
\hline \multirow{2}{*}{\multicolumn{1}{|c|}{ Oral Health Status }} & \multicolumn{2}{c|}{ Group } & Total \\
\cline { 2 - 4 } & Pre-clinical Group & Clinical Group & \\
\hline Good Oral Health (DMFT scores 2-9) & $150(50.5 \%)$ & $147(49.5 \%)$ & $297(78 \%)$ \\
\hline Bad Oral Health (DMFT scores 10-16) & $55(66 \%)$ & $28(33.7 \%)$ & $83(22 \%)$ \\
\hline Total & $205(53.9 \%)$ & $175(46 \%)$ & $380(100 \%)$ \\
\hline
\end{tabular}

Table-II. Comparative frequency of dental caries amongst the dental students in pre-clinical and clinical group.

Statistical analysis for Comparative frequency of dental caries amongst the dental students in pre-clinical and clinical group showed a $\mathrm{p}$ value 0.013 . Thus motivations towards treatment seeking behavior among the clinical group showed marked improvement.

\section{DISCUSSION}

The oral health status of the whole sample of dental students in the present study was good with an average DMFT of $3.5 \%$. In general the present study DMFT was relatively less than the other international studies done on dental students. In 2013 the DMFT of dental students of Zagreb was reported to be $6.97^{14}$, while Spanish dental students with a DMFT of 5.9, around 6 in Barcelona $^{15}$ and 7.97 in King Saud University ${ }^{16}$ respectively. Poland dental students were reported with a DMFT as high as $11.9^{17}$ and 12.8 in saurian ${ }^{18}$, whereas a DMFT of 10 was found in dental population of Kaunas. ${ }^{19}$ Only in one international study carried out in dental students of Tunisia 2006 by Maatouk et al the mean DMFT was less than (2.3) the present study. ${ }^{20}$

So far only two studies of DMFT have been locally reported on dental students. In 2011 study at Liaquat College of Medicine and Dentistry reported a mean DMFT of $1.7^{8}$ followed by a 1.38 scoring of dental population at LMDC in 2013. ${ }^{21}$ In each of the studies the mean DMFT was less or in other words better than the present study's finding. So the local results showed different results. This may be due to local differences among population regarding oral health status and hygiene practices.

According to the present findings, the DMFT scores of the pre-clinical group were high (3.7\%) as compare to the clinical group (3.2\%) with $(p=0.07)$. On defragmentation of the DMFT scorings it was observed that; individual wise the decay $(75 \%)$ was highest followed by filled (53\%) components of the sample and the least was the missing teeth component $(17 \%)$. While considering the total number of teeth with the irreversible DMFT scores, the decay teeth were $64 \%$; filled $30.5 \%$ and $6 \%$ were extracted.

In the group comparison the pre-clinical students had double the caries rate $(44 \%)$ to that of clinical group (20\%). In case of treatment seeking 
behavior; that is the filled (19\%) teeth proportion along with the extractions (4.1\%) was double that of pre-clinical students (Table-I).

When observed within the literature the dental student's community were compared to the equally literate groups of other specialty for sack of reference. In such studies, a significant difference was evident between the oral health status of the students. One such study was conducted in 2013 by Simat et al. The mean DMFT of dental students (6.9) was significantly less than the other students of Zagreb University (8.9). ${ }^{14}$ In 2002 A Spanish survey of oral health of dental and medical students showed a higher DMFT value at the beginning of the study by dental students compared to medical students (5.91 vs. 4.33), with a similar share of active caries in both groups. ${ }^{15}$

In a number of studies oral health status of dental students were compared within the dental training course at different education levels or by difference of clinical skills. In such studies contrary to the present findings, either no significant difference in DMFT scores was evident or an increase in the DMFT was observed.

In a study done in Kaunas 2003 an increase in the DMFT was observed with advancement in dental studies (preclinical DMFT $=9.04$ vs. clinical $=$ 11.03). The author assumed the increase in DMFT was due to an increase in the treatment seeking behavior by the students. ${ }^{19}$ In 2006 dabrowska et al. reported an average DMFT of 11.91 in the first year of Poland's dental students, compare to final years of dentistry with 13.56 DMFT. ${ }^{17}$ Since DMFT only take in account those teeth as "F" that were filled because of caries. Thus a positive treatment seeking behavior was observed but with the reservation that almost $91 \%$ of the students had caries in the first place. Secondly in these studies no specifications of student's inclination towards preventive fillings were made to support the said claim.

Studies were concluded with no significant difference in mean DMFT scores among the preclinical and clinical groups. In agreement with the present study an observation was made about the decay component of the mean DMFT that showed a significantly decrease as compare to the filled component which increased with an advancement in education. ${ }^{11,15}$

Yet in a study conducted in King Saud University, the caries prevalence among the dentistry students was 95.3\%, and the mean DMFT score was 7.97 with decay (D) component of 3.59 missing $(\mathrm{M})$ component of 0.67 and filled component of 3.71. But there was no significant difference in mean DMFT scores of students from various academic levels. ${ }^{16}$

The oral health status of present study population was clearly better than many international studies conducted in past. But on the local level the study sample seems to be having higher DMFT scores. Although unlike these local studies an improvement was evident as decrease in DMFT along with decay component was statistically evident.

Thus in the present study the obvious decline in the DMFT scores depicted an improved oral health status with progression in education level. Especially for the Students in the clinical year appear to have half the amount of caries. Additionally the clinical students had more inclination towards improving oral health status by sorting treatments.

\section{CONCLUSION}

The self-assumed oral hygiene practices of the dental students in Peshawar were statistically found improved as the student's progress through the four years of dental course. These findings were cross analyzed and supported by the practical oral health status of the students when accessed through the Decay, Missing and Filled index.

It was evident from the present study's results that an improvement in oral health status was observed with advancement in dental training.

\section{LIMITATIONS}

In the present study the dental students were 
considered as one sample. A further stratification of sample on the basis of institutional grouping can help better differentiate and compare the oral health status on the bases of old establish and new innovative teaching systems.

\section{Copyright@ 21 Oct, 2019.}

\section{REFRENCES}

1. Moynihan PJ, Kelly SA. Effect on caries of restricting sugars intake: Systematic review to inform WHO guidelines. J Dent Res 2014;93:8-18

2. Bernabé E, Sheiham A. Age, period and cohort trends in caries of permanent teeth in four developed countries. Am J Public Health 2014; 104:e115-21.

3. Peltzer K, Tepirou C, Pengpid S. Prevalence and correlates of perceived teeth health status and oral health behaviour among school-going adolescents in Cambodia. Nagoya J Med Sci, 2016; 78: 493-500.

4. Wagle M, Trovik TA, Basnet P, Acharya G. Do dentists have better oral health compared to general population: a study on oral health status and oral health behavior in Kathmandu, Nepal. BMC Oral Health. 2014; 14:23.

5. Aung EE, Ueno M, Zaitsu T, Kawaguchi Y. Oral health behaviors and related factors in Myanmar population. Dent Health Curr Res, 2015; 1:1.

6. Albino J, Tiwari T. Preventing childhood caries: A review of recent behavioral research. J Dent Res, 2016; 95: 35-42.

7. Sheiham A, James WPT. A reappraisal of the quantitative relationship between sugar intake and dental caries: the need for new criteria for developing goals for sugar intake. BMC public health. 2014; 14(1):863.

8. Nadeem M, Syeda SA, Khaliq R, Mirza H. Evaluation of dental health education and dental status among dental students at Liaquat College of Medicine and Dentistry. Int J of Dent Clin. 2011; 3(3).

9. Vano M1, Gennai S, Karapetsa D, Miceli M, Giuca MR, Gabriele M, Graziani F. The influence of educational level and oral hygiene behaviors on DMFT index and CPITN index in an adult Italian population: an epidemiological study. Int J Dent Hyg. 2015 May; 13(2):151-7.

10. Khan A, ljaz S, Syed A, Qureshi A, Padhiar I, Sufia S. Oral health in Pakistan: A situation analysis. Developing Dentistry. 2004; 5(2):35-44.
11. Critchlow D. Part 2: Oral health care for the housebound patient. Br J Community Nurs. 2017 Jan 2; 22(1):650-657.

12. Halawany HS, Abraham NB, Jacob V, Al-Maflehi N. The perceived concepts of oral health attitudes and behaviors of dental students from four Asian countries. The Saudi J for Den Research. 2015;6:79-85

13. Chher T, Turton BJ, Hak S, Beltran E, Courtel F, Durward $C$, et al. Dental caries experience in Cambodia: Findings from the 2011 Cambodia National Oral Health Survey. J Int Oral Health, 2016; 8: 1-7

14. Šimat S, Mostarčić $K$, Matijević J, Simeon P, Rošin G K, Jukić KS. A comparison of oral status of the Fourthyear students of various colleges at the University of Zagreb. Acta stomatologica Croatica. 2011; 45(3):17783.

15. Cortes FJ, Nevot C, Ramon JM, Cuenca E. The evolution of dental health in dental students at the University of Barcelona. J Dent Educ. 2002 Oct; 66(10):1203-8.

16. Wyne AH, Chohan AN, Al-Motaiby EAA,et al. Dental caries and oral hygiene in male dental students of King Saud University, College of Dentistry, Riyadh. Pak oral and Dent J. 2007; 27: 219-222

17. Peltzer K, Pengpid S. Oral health behaviour and social and health factors in university students from 26 low, middle and high income countries. Int $\mathrm{J}$ Environ Res Public Health, 2014; 11: 12247-12260.

18. Agili DE. A systematic review of population-based dental caries studies among children in Saudi Arabia. The Saudi Dent J. 2013;25:3-11

19. Peltzer K, Pengpid S. Oral and hand hygiene behaviour and risk factors among in-school adolescents in four Southeast Asian countries. Int J Environ Res Public Health, 2014; 11: 2780-2792.

20. Maatouk F, Maatouk W, Ghedira H, Ben Mimoun S. Effect of $\mathbf{5}$ years of dental studies on the oral health of Tunisian dental students. Eastern Mediterranean Health J 2006; 12(5):625-31.

21. Sherazi UM-E-R, Naz F, Yousuf M. DMFT index among dental undergraduates of Lahore Medical and Dental College in different professional years of dentistry. Pak Oral \& Dent J. 2013; 33(1). 


\begin{tabular}{|c|c|c|c|}
\hline \multicolumn{4}{|c|}{ AUTHORSHIP AND CONTRIBUTION DECLARATION } \\
\hline Sr. \# & Author(s) Full Name & Contribution to the paper & Author(s) Signature \\
\hline 1 & Zia Ur Rehman Khalil & Principal investigator. & 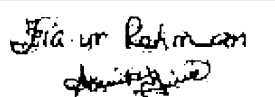 \\
\hline 2 & Aamir Hameed & $\begin{array}{l}\text { Research designing and } \\
\text { drafting. }\end{array}$ & $e$ \\
\hline 3 & Muhammad Raza & Objective setting, Drafting. & \\
\hline 4 & Aliya Khan & Data collection, paper write up. & \\
\hline 5 & Kanwal Nazir & Paper write up, drafting. & 4 \\
\hline 6 & Amjid Khattak & Literature review. & \\
\hline
\end{tabular}

